\title{
Amotivation is associated with smaller ventral striatum volumes in elderly patients with schizophrenia
}

\author{
Fernando Caravaggio, PhD ${ }^{a, b}$, Gagan Fervaha, PhD $^{a}$, Yusuke Iwata, M.D. ${ }^{a, b}$, Eric Plitman, \\ B.Sc. ${ }^{a}$, Jun Ku Chung, B.Sc. ${ }^{a}$, Shinichiro Nakajima, M.D., PhDa, Wanna Mar, B.Sc., M.A. ${ }^{a}$, \\ Philip Gerretsen, MSW., M.D., PhD ${ }^{\mathrm{a}, \mathrm{b}}$, Julia Kim, B.Sc. ${ }^{\mathrm{a}}$, M. Mallar Chakravarty, PhD ${ }^{\mathrm{c}, \mathrm{d}, \mathrm{e} \text {, }}$ \\ Benoit Mulsant, MD., MS. ${ }^{b}$, Bruce Pollock, MD., PhD ${ }^{b}$, David Mamo, MD., PhD ${ }^{f}$, Gary \\ Remington, M.D., PhD ${ }^{a, b}$, and Ariel Graff-Guerrero, M.D., PhD. ${ }^{a, b}$

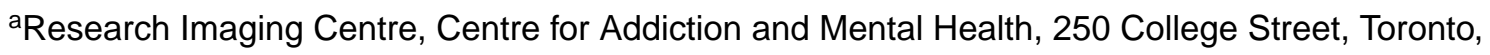 \\ Ontario, Canada. M5T 1R8 \\ bDepartment of Psychiatry, University of Toronto, 250 College Street, Toronto, Ontario, Canada. \\ M5T 1 R8 \\ 'Department of Biological \& Biomedical Engineering, McGill University, Montreal, Quebec, \\ Canada. $\mathrm{H} 4 \mathrm{H} 1 \mathrm{R} 3$ \\ ${ }^{\mathrm{d} C e r e b r a l ~ I m a g i n g ~ C e n t r e, ~ D o u g l a s ~ M e n t a l ~ H e a l t h ~ I n s t i t u t e, ~ M c G i l l ~ U n i v e r s i t y, ~ M o n t r e a l, ~ Q u e b e c, ~}$ \\ Canada. $\mathrm{H} 4 \mathrm{H} 1 \mathrm{R} 3$ \\ 'Department of Psychiatry, McGill University, Montreal, Quebec, Canada. H4H 1R3 \\ fDepartment of Psychiatry, University of Malta, Malta
}

\begin{abstract}
Objective-Motivational deficits are prevalent in patients with schizophrenia, persist despite antipsychotic treatment, and predict long-term outcomes. Evidence suggests that patients with greater amotivation have smaller ventral striatum (VS) volumes. We wished to replicate this finding in a sample of older, chronically medicated patients with schizophrenia. Using structural imaging and positron emission tomography (PET), we examined whether amotivation uniquely predicted VS volumes beyond the effects of striatal dopamine (DA) $D_{2 / 3}$ receptor $\left(D_{2 / 3} R\right)$ blockade by antipsychotics.
\end{abstract}

\begin{abstract}
Methods-Data from 41 elderly schizophrenia patients (mean age: $60.2 \pm 6.7 ; 11$ female) were reanalyzed from previously published imaging data. We constructed multivariate linear step-wise regression models with VS volumes as the dependent variable, and various sociodemographic and clinical variables as the initial predictors: age, gender, total brain volume, and antipsychotic striatal $\mathrm{D}_{2 / 3} \mathrm{R}$ occupancy. Amotivation was included as a subsequent step to determine any unique
\end{abstract}

Corresponding Author: Dr. Ariel Graff-Guerrero. Centre for Addiction and Mental Health. 80 Workman Way, $6^{\text {th }}$ Floor. Toronto, ON M6J1H4. Canada. ariel.graff@camh.ca.

Disclosures

No other disclosures were reported.

Conflict of Interests

The other authors have no conflicts of interest to declare in relation to the current manuscript. 
relationships with VS volumes beyond the contribution of the covariates. In a reduced sample $(\mathrm{n}=36)$, general cognition was also included as a covariate.

Results-Amotivation uniquely explained $8 \%$ and $6 \%$ of the variance in right and left VS volumes, respectively (right: $\beta=-.38, t=-2.48, p=.01$; left: $\beta=-.31, t=-2.17, p=.03$ ). Considering cognition, amotivation levels uniquely explained $9 \%$ of the variance in right VS volumes ( $\beta=-.43$, $t=-.26, p=.03)$.

Conclusion-We replicate and extend the finding of reduced VS volumes with greater amotivation. We demonstrate this relationship uniquely beyond the potential contributions of striatal $\mathrm{D}_{2 / 3} \mathrm{R}$ blockade by antipsychotics. Elucidating the structural correlates of amotivation in schizophrenia may help develop treatments for this presently irremediable deficit.

\section{Introduction}

Motivational deficits in patients with schizophrenia are persistent ${ }^{1}$, prevalent from the earliest stages of the disease ${ }^{2}$, and may uniquely predict outcomes beyond other symptoms $^{3-6}$. Across several neuropsychiatric disorders, including schizophrenia ${ }^{7}$, amotivation is associated with abnormal functioning of frontal-striatal circuits involving the dorsolateral prefrontal cortex (DLPFC), anterior cingulate cortex (ACC), and ventral striatum $(\mathrm{VS})^{8-10}$. In schizophrenia, amotivation has been associated with reduced frontal lobe volumes ${ }^{11}$, and cortical thinning in the left ACC and left orbitofrontal cortex ${ }^{12}$. A better understanding of the neurochemical and structural correlates of amotivation in patients with schizophrenia may help guide future treatments for this currently unamenable deficit, which severely impacts everyday functioning.

While several studies have focused on the cortex, few studies have specifically examined the relationship between VS morphology and amotivation in patients with schizophrenia.

Examination of the VS as a substrate for amotivation in schizophrenia is particularly relevant given its proposed role in regulating motivated behaviour ${ }^{10,13}$. To our knowledge, only one study by Roth and colleagues has specifically explored this relationship ${ }^{14}$. They observed that patients $(\mathrm{n}=23)$ with more severe amotivation demonstrated reduced grey matter (GM) volumes in the right VS. While several lines of preclinical evidence suggest that reduced dopamine (DA) functioning at $D_{2 / 3}$ receptors $\left(D_{2 / 3} R\right)$ in the VS increases amotivation ${ }^{7,15,16}$, there have been mixed observations in schizophrenia. In untreated patients, greater amotivation has been associated with lower endogenous DA at $\mathrm{D}_{2 / 3} \mathrm{R}$ in the VS $\left(\mathrm{r}^{2}=.47, p=\right.$. $001)^{17}$. However, treatment with antipsychotics, which antagonize $D_{2 / 3} R$, does not seem to significantly worsen nor improve motivational deficits in patients with schizophrenia ${ }^{18}$.

Consistently, several studies suggest that occupancy of striatal $\mathrm{D}_{2 / 3} \mathrm{R}$ by antipsychotics is related to improvements in positive symptoms, with no relationship to negative symptoms ${ }^{19-22}$. In a sample of elderly, chronically treated patients, estimated antipsychotic occupancy of $\mathrm{D}_{2 / 3} \mathrm{R}$ in the VS was not found to be related to amotivation ${ }^{23}$. Reducing the dose of antipsychotics in the same sample failed to significantly improve motivation. Thus, the functional status of striatal $\mathrm{D}_{2 / 3} \mathrm{R}$ in motivated behaviour may be different in patients with schizophrenia who are treated acutely versus chronically with antipsychotics. 
We wished to replicate previous findings of a relationship between reduced VS volumes and greater amotivation in a sample of elderly, chronically medicated patients with schizophrenia. This would help inform whether reduced VS volumes are a correlate of amotivation across the lifespan. We wanted to examine this relationship whilst controlling for estimated striatal $\mathrm{D}_{2 / 3} \mathrm{R}$ occupancy by antipsychotic drugs, evaluated using positron emission tomography (PET). This would help elucidate whether antipsychotic $\mathrm{D}_{2 / 3} \mathrm{R}$ blockade modulates the relationship between motivation and brain morphology. Notably, estimated striatal $\mathrm{D}_{2 / 3} \mathrm{R}$ occupancy provides a more biologically and clinically relevant correlate of antipsychotic action in the brain than dose ${ }^{24}$. Thus, above and beyond the effects of antipsychotic induced striatal $\mathrm{D}_{2 / 3} \mathrm{R}$ blockade, we hypothesized that levels of amotivation would be negatively correlated with VS volume.

\section{Methods}

Participants

This is an extension of a previous study; the methods and main results have been published elsewhere ${ }^{25}$. Patients were recruited based on the following: 1) DSM-IV diagnosis of schizophrenia or schizoaffective disorder, confirmed by the SCID Axis I Disorders $\left.{ }^{26}, 2\right) \geq 50$ years old, 3) clinically stable (i.e., no inpatient hospitalization in the past 6 months), and, 4) receiving the same dose of risperidone or olanzapine monotherapy for at least 6 months. Exclusion included: meeting criteria for a substance-use disorder (past 6 months), a positive urine screen for substances of abuse, changing their dose of any psychotropic for mental health reasons (past 6 months), and having an unstable medical condition. Fourteen subjects were current smokers: (mean $\pm \mathrm{SD}) 8 \pm 15$ cigarettes a day.

The study was approved by the institutional Research Ethics Board at the Centre for Addiction and Mental Health, authorized by Health Canada, and registered at ClinicalTrials.gov (NCT00716755). All participants provided written informed consent. Competence to consent was determined using the MacCAT-CR ${ }^{27}$.

\section{PET Imaging}

$\left[{ }^{11} \mathrm{C}\right]$-raclopride scans were acquired on a CPS-HRRT PET camera, measuring radioactivity in 207 brain slices with a thickness of $1.2 \mathrm{~mm}$ each. The in-plane resolution was $\sim 2.8 \mathrm{~mm}$ full-width at half-maximum. Transmission scans were acquired using a single photon point source for attenuation correction $\left({ }^{137} \mathrm{Cs} ; \mathrm{T}_{1 / 2}=30.2 \mathrm{yr}, \mathrm{E}=662 \mathrm{KeV}\right)$. A custom-fitted thermoplastic mask was used to decrease head-motion. The mass injected, radioactivity dose, and specific activity of $\left[{ }^{11} \mathrm{C}\right]$-raclopride was $2.71( \pm 1.96) \mu \mathrm{g}, 9.69( \pm 0.79) \mathrm{mCi}$, and $1650.89( \pm 701.51) \mathrm{mCi} / \mu \mathrm{mol}$. Emission data were acquired in list-mode for 60 minutes, reconstructed by filtered back projection, and redefined into 28 frames.

Time activity curves (TACs) were obtained from dynamic PET images co-registered to MRIs, using the normalized mutual-information algorithm ${ }^{28}$ in SPM2 (http:// www.fil.ion.ucl.ac.uk/spm). The Simplified Reference Tissue Method (SRTM ${ }^{29}$ was used to calculate binding potential non-displaceable $\left(\mathrm{BP}_{\mathrm{ND}}\right)^{30}$ using cerebellum as reference. The basis function of the $\mathrm{SRTM}^{31}$ was applied to generate parametric $\mathrm{BP}_{\mathrm{ND}}$ maps using PMOD 
(v2.7). Images were spatially normalized into MNI space by Nearest Neighbour Interpolation (voxel-size $2 \mathrm{~mm}^{3}$ ) using SPM2.

\section{Estimated Striatal $D_{2 / 3} R$ Occupancy}

We were not able to obtain $\mathrm{BP}_{\mathrm{ND}}$ data from our participants while they were off antipsychotics. To compute $\mathrm{D}_{2 / 3} \mathrm{R}$ occupancy, we estimated participants' baseline $\mathrm{BP}_{\mathrm{ND}}$ values using data from antipsychotic-free patients with schizophrenia as a reference (mean \pm SD; age: $66.1 \pm 11.5$ years; age range: $50-83$ years; 4 women; duration of antipsychotic-free state: $12.5 \pm 18.6$ years), as previously employed ${ }^{32-34}$. These subjects come from a previously published study examining $D_{2 / 3} R$ availability in elderly patients with schizophrenia who had been antipsychotic free for an extended period ${ }^{35}$. This study demonstrated $\mathrm{D}_{2 / 3} \mathrm{R}$ availability measured with $\left[{ }^{11} \mathrm{C}\right]$-raclopride in un-medicated, elderly patients with schizophrenia did not differ from age- and sex-matched healthy controls. Using this antipsychotic-free sample, age- and sex-corrected measures of baseline $\mathrm{BP}_{\mathrm{ND}}$ were estimated for each $\mathrm{ROI}$ using a linear regression equation ${ }^{35} . \mathrm{D}_{2 / 3} \mathrm{R}$ occupancy was calculated using the following formula:

$\mathrm{D}_{2 / 3} \mathrm{R}$ occupancy $=\left(\left[\mathrm{BP}_{\mathrm{ND} \text { - Antipsychotic-free }}-\mathrm{BP}_{\mathrm{ND} \text { - Medicated }}\right] /\left[\mathrm{BP}_{\mathrm{ND} \text { - Antipsychotic-free }}\right]\right) \times 100$

where $\mathrm{BP}_{\mathrm{ND} \_ \text {Antipsychotic-free }}$ is the age- and sex-corrected $\mathrm{BP} \mathrm{ND}_{\mathrm{ND}}$ derived from antipsychoticfree participants with schizophrenia, and $\mathrm{BP}_{\mathrm{ND} \_ \text {Medicated }}$ is the $\mathrm{BP}_{\mathrm{ND}}$ obtained from participants receiving oral risperidone or olanzapine. Since it is often impossible to have a complete wash-out of antipsychotic medications to provide a true baseline PET scan in patients with schizophrenia, this estimation method has been employed by our research group $^{36-38}$ and several others ${ }^{32-34}$. It has been suggested that the error associated with this estimation ranges from $0-9 \%$ for patients with $50 \%$ occupancy, and $0-4 \%$ for patients who have $80 \%$ occupancy ${ }^{32,39}$. This source of error is unlikely to introduce a systematic bias across subjects.

\section{Magnetic Resonance Imaging (MRI)}

Each participant underwent T1-weighted magnetic resonance imaging (MRI; inversion time, 650 milliseconds; field of view, $23 \mathrm{~cm}$; $256 \times 256$; slice thickness, $0.9 \mathrm{~mm}$; flip angle, $8^{\circ}$ ), performed on a GE Discovery MR750 3.0-T scanner (General Electric Medical Systems).

\section{Subcortical Volume Analyses}

The Multiple Automatically Generated Templates (MAGeT-Brain) algorithm ${ }^{40,41}$ was employed to provide fully-automated segmentation of striatal subdivisions in participants' native space ${ }^{42}$. The MAGeT-Brain algorithm is a modified multi-atlas segmentation technique, which employs a limited number of high-quality manually segmented atlases as an input to reduce bias and enhance segmentation accuracy. MAGeT-Brain propagates atlas segmentations to a template library, formed from a subset of target images, via transformations estimated by nonlinear image registration. The resulting segmentations are then propagated to each target image and fused using a label fusion method. 
A subset of subjects $(n=21)$ were used as template libraries through which the final segmentation was bootstrapped; chosen based on representative subject characteristics ${ }^{43}$. Volumes $\left(\mathrm{mm}^{3}\right)$ were extracted bilaterally from the VS and the whole striatum. Figure 1 in the Supplementary Material demonstrates the results of the automatic striatal subdivision labelling in a single subject.

\section{Total Brain Volume Analysis}

The procedure for total brain volume (TBV) analysis has been published elsewhere ${ }^{44}$ TBV was obtained using the Brain Extraction based on non-local Segmentation Technique (BEaST) method ${ }^{45}$. This includes CSF (in the ventricles, cerebellar cistern, deep sulci, along surface of brain, and brainstem), the brainstem, and cerebellar white matter and GM in the brain mask, while excluding the skull, skin, fat, muscles, dura, eyes, bone, exterior blood vessels, and exterior nerves.

\section{Symptom Assessments}

Clinical status was evaluated using the Positive and Negative Syndrome Scale (PANSS) ${ }^{46}$, and symptom scores were evaluated using consensus-defined factors ${ }^{47}$. Given the burgeoning evidence for a two-factor structure of negative symptoms in schizophrenia ${ }^{48,49}$, we calculated two additional scores to evaluate amotivation and expressive deficits separately. Specifically, a social amotivation score (Amotivation Factor) was derived by summing the following items from the PANSS: Emotional Withdrawal, Passive Apathetic Withdrawal, and Active Social Avoidance ${ }^{50}$. A diminished expression score (Diminished Expression Factor) was calculated by summing the following items from the PANSS: Blunted Affect, Poor Rapport, Lack of Spontaneity \& Flow of Conversation, and Motor Retardation ${ }^{50}$. Higher scores on each of these measures reflect greater negative symptom severity. Cognitive functioning was assessed using The Repeatable Battery for the Assessment of Neuropsychological Status (RBANS) ${ }^{51}$. Given this previous literature elucidating the factor analytic structure of PANSS negative symptoms, we did not explore how modifications (i.e., removing certain items) to factor scores could affect our results.

\section{Statistical Analysis}

Statistical analyses were conducted using IBM SPSS (v.20) and GraphPad Prism (v.7.0). Normality of variables was determined using the D'Agostino-Pearson test. Our analyses focused on VS volumes as the main outcome variable for each hemisphere separately, as previous work found a specific relationship between amotivation and right VS volume ${ }^{14}$. We constructed multivariate linear step-wise regression models with VS volumes as the dependent variable, and various sociodemographic and clinical variables as the initial predictors. Amotivation was included as a subsequent step in this predictive model to determine whether this variable demonstrated a significant relationship with VS volumes over and above the contribution of other covariates. Roth and colleagues included age, gender, depression and total GM as covariates. We extended this list to include age, gender, TBV and striatal $\mathrm{D}_{2 / 3} \mathrm{R}$ occupancy as an initial step, and positive and depressive symptoms as the second. Amotivation scores were included as the third step. Several groups, including ourselves, have demonstrated that while amotivation and cognition are distinct constructs, they have some shared variance ${ }^{5}$. Thus, we wished to explore whether the relationship 
between amotivation and VS volume would persist considering the potential variance in amotivation accounted for by cognition. A subset of the sample also had cognitive scores available. For these subjects, we recomputed our models including global cognition in the second step to determine whether the relationship of interest would hold while controlling for this variable as well. In the Supplementary Material, we present the correlations between all the variables included in our multivariate regression models. In our current sample, there is a trend correlation $(p=.08)$ between amotivation and RBANS total scores. Moreover, $\mathrm{D}_{2 / 3} \mathrm{R}$ occupancy is negatively correlated with VS volumes and TBV. While this is consistent with some (but not all) findings that antipsychotic exposure is related to reductions in both striatal volume and $\mathrm{TBV}^{52,53}$, our sample is not poised to directly address causality regarding the issue of how antipsychotic exposure may change brain morphology in schizophrenia.

We conducted several analyses to explore the specificity of the amotivation-VS volume relationship. Specifically, we recomputed the above analyses with total striatal volume as the dependent variable. In addition, in separate models, we explored whether another negative symptom, namely diminished expression, would be related to VS volumes.

The alpha level of significance for all our a priori hypotheses and confirmatory analyses was set at $p<.05$ (two-tailed).

\section{Results}

Participant characteristics are detailed in Table 1. In our multivariate regression model (see Table 2), age, gender, $\mathrm{TBV}$, and striatal $\mathrm{D}_{2 / 3} \mathrm{R}$ occupancy together explained $47 \%$ of the variance in right VS volumes. Considering these variables, in addition to positive and depression symptoms, amotivation significantly explained an additional $8 \%$ of the variance in right VS volumes. Thus, over and above the contribution of participant characteristics, striatal $\mathrm{D}_{2 / 3} \mathrm{R}$ occupancy, positive symptoms, and depression symptoms, levels of amotivation were negatively associated with right VS volumes (see Figure 1a). Similarly, in the left VS amotivation significantly explained an additional $6 \%$ of the variance above and beyond that explained by the other variables (see Table $2 \&$ Figure $1 b$ ). Since years of education and the number of cigarettes smoked per day could theoretically influence the relationship between symptoms and VS volume, we explored including these variables as an additional step in our multivariate regression model (see Supplementary Material).

We wished to explore whether amotivation could account for a significant proportion of the variance in VS volumes after considering global cognitive functioning assessed with total RBANS scores. Five participants did not provide total RBANS scores. After considering global cognitive functioning, amotivation continued to explain a significant proportion (9\%) of the variance in right VS volumes, but not left VS volumes (see Table 3). Since there could be potential interactions between cognition and symptomatology on brain morphology, we explored whether amotivation could continue to account for a significant proportion of the variance in right VS volumes after the inclusion of cognition*symptom interaction terms. Amotivation continued to explain a significant proportion (9\%) of the variance in right VS 
volumes, but not left VS volumes, after considering these potential interactions (see Table 4).

We explored the specificity of our findings to amotivation, rather than to other negative symptoms. We constructed separate regression models using diminished expression scores instead of amotivation scores as the final predictive step (these negative symptoms were positively correlated with each other: $\mathrm{r}=.75, p<.0001)$. Notably, diminished expression scores failed to account for any additional variance in right (final step: $\beta=.13, t=.81, p=.42$; overall model: $\mathrm{r}^{2}=.37, \mathrm{~F}_{1,33}=.66, p=.42$ ) and left (final step: $\beta=.02, t=.15, p=.88$; overall model: $\mathrm{r}^{2}=.54, \mathrm{~F}_{1,33}=.02, p=.88$ ) VS volumes. We explored whether the effect with amotivation was specific to the VS, rather than the striatum in general. Amotivation scores failed to account for any additional variance in left (final step: $\beta=-.13, t=-.91, p=.37$; overall model: $\mathrm{r}^{2}=.60, \mathrm{~F}_{1,33}=.83, p=.37$ ) and right (final step: $\beta=-.17, t=-1.19, p=.24$; overall model: $\left.\mathrm{r}^{2}=.61, \mathrm{~F}_{1,33}=1.41, p=.24\right)$ total striatal volume.

\section{Discussion}

We found amotivation in elderly, chronically medicated patients with schizophrenia is significantly related to smaller VS volumes. This relationship persisted after considering several a priori variables often associated with amotivation and brain morphology. These findings are consistent with the theorized role of the VS in motivation ${ }^{16}$, and replicates and extends previous findings ${ }^{14}$. Controlling for age, gender, depression (BDI-II scores), and total GM, Roth and colleagues found that amotivation, measured with the Apathy Evaluation Scale, was associated with smaller right VS volumes in schizophrenia patients. Using different volumetric quantification methods, and a different measure of amotivation, we replicate these findings while additionally controlling for general positive symptoms and estimated antipsychotic $\mathrm{D}_{2 / 3} \mathrm{R}$ occupancy. Thus, our data suggests that amotivation is uniquely associated with reduced VS volumes, above and beyond striatal $\mathrm{D}_{2 / 3} \mathrm{R}$ blockade by antipsychotics.

Besides including estimated striatal $\mathrm{D}_{2 / 3} \mathrm{R}$ occupancy, our study has several strengths which serve to extend previously published work. First, our study included additional covariates positive symptom severity and cognition - and found the relationship between amotivation and VS volumes to hold even after statistically controlling for these. Second, our study examined the specificity of this relationship. We failed to find an association between negative symptoms in general and VS volumes. Rather, the relationship was specific to amotivation. Furthermore, the relationship between amotivation and striatal morphology was specific to the VS, as a significant association was not observed with total striatal volumes. Collectively, this study provides a more comprehensive approach to the question of whether amotivation is related to VS morphology in schizophrenia; suggesting a specific relationship. An additional strength is that the patients in our sample were clinically stable, and had received the same dose of medication monotherapy for the last 6 months.

Several functional MRI studies have linked amotivation in schizophrenia with reduced activation of the VS ${ }^{54-56}$. Our findings raise the possibility that previously reported VS hypoactivation may be the result of, or related to, reduced VS volume. The neurofunctional 
significance of reduced VS volumes in schizophrenia remains unclear. Future studies should employ multimodal brain imaging to determine whether amotivation-associated reductions in VS activation is associated with reduced neuronal integrity and/or reduced endogenous DA levels. A better understanding of the biological mechanisms underlying reduced VS volume and activity may help guide future treatments for amotivation in schizophrenia. For example, these findings support theories that deep brain stimulation of the VS may improve motivational deficits in schizophrenia ${ }^{57-59}$, as in depression ${ }^{60}$. Volumetric reductions are usually interpreted as reflecting neurodegeneration. However, multiple interpretations exist. In healthy persons, several common genetic variants have been associated with natural variation in putamen and caudate volumes, but not VS volumes ${ }^{61}$. In rodents, reductions in cortical and striatal volume have been related to reduced markers of GABA neuron expression/function ${ }^{62-64}$. We speculate that reduced GABA-ergic interneuron expression, structure, or function in the VS may be related to greater amotivation. However, this speculation requires confirmation by future longitudinal studies combining in vivo MRI volume measures with post-mortem measures.

Both our study and Roth et. al's found that amotivation was more strongly related to VS morphology in the right hemisphere versus the left. The reason for this laterality effect remains unclear. Evidence suggest that DA release in the right VS may be more strongly related to processing of un-expected monetary rewards ${ }^{65}$. Moreover, functional connectivity data suggests that the left VS may be more strongly related to internally directed processes (i.e., saliency and self-control), while the right VS may be related to externally directed processes (i.e., action/attention toward behavioural contingencies) ${ }^{66}$. Interestingly, reduced glucose metabolism in the right VS, but not the left, is predictive of increased amotivation after deep-brain stimulation of the subthalamic nucleus in Parkinson's disease ${ }^{67}$. Collectively, we tentatively speculate that the right VS may be more strongly related to motivated behaviour (i.e., translating reward contingencies into action). However, larger studies are needed to clarify the role of VS laterality on amotivation in healthy persons and those with neuropsychiatric diseases.

There are several limitations. First, included patients were 250 years of age. While our findings replicate those observed in younger patients, the generalizability of our findings may still be limited. Our assessment of motivational deficits was incomplete: only clinician rated and evaluating a single domain (i.e., social amotivation). Future studies should employ multiple measures of amotivation, including objective task measures ${ }^{7}$. Future studies should include matched healthy controls to fully characterize how differences in VS volume may relate to differences in motivation. Finally, while our estimate of antipsychotic $D_{2 / 3} R$ blockade is superior to estimated chlorpromazine dose-equivalents, patients did not provide a true baseline PET scan. In the Supplementary Material, we provide our main analyses of interest using chlorpromazine equivalents instead of occupancy to allow comparison with future studies that may use this measure. Prospective longitudinal PET studies including neuroleptic naïve patients could examine the relationships between $\mathrm{D}_{2 / 3} \mathrm{R}$ blockade, amotivation, and brain morphology. Finally, the variables included in our regression models were based on previous work, and were a priori. Studies with larger sample sizes and sufficient statistical power should explore whether other variables may mediate the relationship between amotivation and VS volume in schizophrenia. 
Our data suggests reduced VS volumes are associated with amotivation in elderly patients with schizophrenia. This relationship was not found to be significantly related to striatal $\mathrm{D}_{2 / 3} \mathrm{R}$ blockade by antipsychotics. Our findings add to a growing literature aimed at better understanding the neural correlates of amotivation in schizophrenia. These findings may help guide novel treatments for this currently unamenable, debilitating symptom.

\title{
Supplementary Material
}

Refer to Web version on PubMed Central for supplementary material.

\section{Acknowledgments}

\author{
Funding/support \\ This work was supported by the Canadian Institutes of Health Research (MOP-97946) and US National Institutes of \\ Health (RO1MH084886). \\ Dr. Graff-Guerrero has received research support from the Canadian Institutes of Health Research (CIHR), US \\ National Institutes of Health (NIH), Ontario Mental Health Foundation (OMHF), Brain and Behavior Research \\ Foundation, Mexico Instituto de Ciencia y Tecnologia del Distrito Federal and Consejo Nacional de Ciencia y \\ Tecnologia, and W. Garfield Weston Foundation. Dr. Mulsant currently receives research funding from Brain \\ Canada, the Centre for Addiction and Mental Health (CAMH) Foundation, the CIHR, and the US NIH. During the \\ past 5 years, he received research support from Bristol-Myers Squibb, Eli-Lilly and Company, and Pfizer (all for \\ medications used in NIH-funded clinical trials). He directly own stocks of General Electric $(<\$ 5000)$. Dr. Nakajima \\ has received fellowship grants from the CIHR, Japan Society for the Promotion of Science, and Nakatomi \\ Foundation and manuscript fees from Dainippon-Sumitomo Pharma and Kyowa Hakko Kirin. Dr. Gerretsen has \\ received fellowship support from the CAMH Foundation, OMHF, and the CIHR Foundation. Dr. Mamo has \\ received investigator initiated grant support from Pfizer.
}

\section{References}

1. Remington G, Foussias G, Fervaha G, et al. Treating Negative Symptoms in Schizophrenia: an Update. Current treatment options in psychiatry. 2016; 3:133-150. [PubMed: 27376016]

2. Lam M, Abdul Rashid NA, Lee SA, et al. Baseline social amotivation predicts 1-year functioning in UHR subjects: A validation and prospective investigation. European neuropsychopharmacology : the journal of the European College of Neuropsychopharmacology. 2015; 25(12):2187-2196. [PubMed: 26553972]

3. Fervaha G, Foussias G, Agid O, Remington G. Motivational deficits in early schizophrenia: prevalent, persistent, and key determinants of functional outcome. Schizophrenia research. 2015; 166(1-3):9-16. [PubMed: 25982811]

4. Fervaha G, Takeuchi H, Foussias G, Hahn MK, Agid O, Remington G. Achievement motivation in early schizophrenia: Relationship with symptoms, cognition and functional outcome. Early intervention in psychiatry. 2017

5. Fervaha G, Zakzanis KK, Foussias G, Graff-Guerrero A, Agid O, Remington G. Motivational deficits and cognitive test performance in schizophrenia. JAMA psychiatry. 2014; 71(9):1058-1065. [PubMed: 25075930]

6. Fervaha G, Siddiqui I, Foussias G, Agid O, Remington G. Motivation and Social Cognition in Patients with Schizophrenia. Journal of the International Neuropsychological Society : JINS. 2015; 21(6):436-443. [PubMed: 26135736]

7. Fervaha G, Foussias G, Agid O, Remington G. Neural substrates underlying effort computation in schizophrenia. Neuroscience and biobehavioral reviews. 2013; 37(10 Pt 2):2649-2665. [PubMed: 24035741]

8. Kos C, van Tol MJ, Marsman JB, Knegtering H, Aleman A. Neural correlates of apathy in patients with neurodegenerative disorders, acquired brain injury, and psychiatric disorders. Neuroscience and biobehavioral reviews. 2016; 69:381-401. [PubMed: 27527825] 
9. Sallet J, Mars R, Quilodran R, Procyk E, Petrides M, Rushworth M. Neuroanatomical basis of motivational and cognitive control: a focus on the medial and lateral prefrontal cortex. Neural basis of motivational and cognitive control. 2011:5-20.

10. Le Heron C, Apps MAJ, Husain M. The anatomy of apathy: A neurocognitive framework for amotivated behaviour. Neuropsychologia. 2017

11. Roth RM, Flashman LA, Saykin AJ, McAllister TW, Vidaver R. Apathy in schizophrenia: reduced frontal lobe volume and neuropsychological deficits. The American journal of psychiatry. 2004; 161(1):157-159. [PubMed: 14702265]

12. Morch-Johnsen L, Nesvag R, Faerden A, et al. Brain structure abnormalities in first-episode psychosis patients with persistent apathy. Schizophrenia research. 2015; 164(1-3):59-64. [PubMed: 25818626]

13. Haber SN, Knutson B. The reward circuit: linking primate anatomy and human imaging. Neuropsychopharmacology : official publication of the American College of Neuropsychopharmacology. 2010; 35(1):4-26. [PubMed: 19812543]

14. Roth RM, Garlinghouse MA, Flashman LA, et al. Apathy Is Associated With Ventral Striatum Volume in Schizophrenia Spectrum Disorder. The Journal of neuropsychiatry and clinical neurosciences. 2016; 28(3):191-194. [PubMed: 26900738]

15. Treadway MT, Zald DH. Reconsidering anhedonia in depression: Lessons from translational neuroscience. Neuroscience \& Biobehavioral Reviews. 2011; 35(3):537-555. [PubMed: 20603146]

16. Salamone John D, Correa M. The Mysterious Motivational Functions of Mesolimbic Dopamine. Neuron. 2012; 76(3):470-485. [PubMed: 23141060]

17. Kegeles LS, Abi-Dargham A, Frankle W, et al. Increased synaptic dopamine function in associative regions of the striatum in schizophrenia. Archives of General Psychiatry. 2010; 67(3):231-239. [PubMed: 20194823]

18. Fervaha G, Takeuchi H, Lee J, et al. Antipsychotics and amotivation. Neuropsychopharmacology : official publication of the American College of Neuropsychopharmacology. 2015; 40(6):15391548. [PubMed: 25567425]

19. Wulff S, Pinborg LH, Svarer C, et al. Striatal D(2/3) Binding Potential Values in Drug-Naïve FirstEpisode Schizophrenia Patients Correlate With Treatment Outcome. Schizophr Bull. 2015; 41(5): 1143-1152. [PubMed: 25698711]

20. Kapur S, Zipursky R, Jones C, Remington G, Houle S. Relationship between dopamine D(2) occupancy, clinical response, and side effects: a double-blind PET study of first-episode schizophrenia. The American journal of psychiatry. 2000; 157(4):514-520. [PubMed: 10739409]

21. Agid O, Mamo D, Ginovart N, et al. Striatal vs extrastriatal dopamine D2 receptors in antipsychotic response-a double-blind PET study in schizophrenia. Neuropsychopharmacology : official publication of the American College of Neuropsychopharmacology. 2007; 32(6):12091215. [PubMed: 17077809]

22. Kegeles LS, Slifstein M, Frankle WG, et al. Dose-occupancy study of striatal and extrastriatal dopamine D2 receptors by aripiprazole in schizophrenia with PET and [18F]fallypride. Neuropsychopharmacology : official publication of the American College of Neuropsychopharmacology. 2008; 33(13):3111-3125. [PubMed: 18418366]

23. Fervaha G, Caravaggio F, Mamo DC, et al. Lack of association between dopaminergic antagonism and negative symptoms in schizophrenia: a positron emission tomography dopamine D2/3 receptor occupancy study. Psychopharmacology. 2016; 233(21-22):3803-3813. [PubMed: 27557949]

24. Uchida H, Takeuchi H, Graff-Guerrero A, Suzuki T, Watanabe K, Mamo DC. Dopamine D2 receptor occupancy and clinical effects: a systematic review and pooled analysis. Journal of clinical psychopharmacology. 2011; 31(4):497-502. [PubMed: 21694629]

25. Graff-Guerrero A, Rajji TK, Mulsant BH, et al. Evaluation of Antipsychotic Dose Reduction in Late-Life Schizophrenia: A Prospective Dopamine D2/3 Receptor Occupancy Study. JAMA psychiatry. 2015; 72(9):927-934. [PubMed: 26131622]

26. First, MB., Spitzer, RL., Gibbon, M., Williams, JBW. Structured Clinical Interview for DSM-IVTR Axis I Disorders, Research Version, Patient Edition (SCID-I/P). New York, NY: New York State Psychiatric Institute; 2002. 
27. Appelbaum, PS., Grisso, T. MacArthur competence assessment tool for clinical research (MacCATCR). Sarasota, FL: Professional Resource Press; 2001.

28. Studholme C, Hill DL, Hawkes DJ. Automated three-dimensional registration of magnetic resonance and positron emission tomography brain images by multiresolution optimization of voxel similarity measures. Medical Physics. 1997; 24(1):25-35. [PubMed: 9029539]

29. Lammertsma AA, Hume SP. Simplified reference tissue model for PET receptor studies. Neuroimage. 1996; 4(3 Pt 1):153-158. [PubMed: 9345505]

30. Innis RB, Cunningham VJ, Delforge J, et al. Consensus nomenclature for in vivo imaging of reversibly binding radioligands. Journal of Cerebral Blood Flow and Metabolism. 2007; 27(9): 1533-1539. [PubMed: 17519979]

31. Gunn RN, Lammertsma AA, Hume SP, Cunningham VJ. Parametric imaging of ligand-receptor binding in PET using a simplified reference region model. Neuroimage. 1997; 6(4):279-287. [PubMed: 9417971]

32. Farde L, Nordstrom AL, Wiesel FA, Pauli S, Halldin C, Sedvall G. Positron emission tomographic analysis of central D1 and D2 dopamine receptor occupancy in patients treated with classical neuroleptics and clozapine. Relation to extrapyramidal side effects. Arch Gen Psychiatry. 1992; 49(7):538-544. [PubMed: 1352677]

33. Farde L, Suhara T, Nyberg S, et al. A PET-study of [11C]FLB 457 binding to extrastriatal D2dopamine receptors in healthy subjects and antipsychotic drug-treated patients. Psychopharmacology. 1997; 133(4):396-404. [PubMed: 9372541]

34. Vernaleken I, Janouschek H, Raptis M, et al. Dopamine D2/3 receptor occupancy by quetiapine in striatal and extrastriatal areas. The international journal of neuropsychopharmacology. 2010; 13(7):951-960. [PubMed: 20392299]

35. Nakajima S, Caravaggio F, Mamo DC, et al. Dopamine D(2)/(3) receptor availability in the striatum of antipsychotic-free older patients with schizophrenia-A [(1)(1)C]-raclopride PET study. Schizophrenia research. 2015; 164(1-3):263-267. [PubMed: 25757713]

36. Suzuki T, Graff-Guerrero A, Uchida H, et al. Dopamine $D(2) /(3)$ occupancy of ziprasidone across a day: a within-subject PET study. Psychopharmacology. 2013; 228(1):43-51. [PubMed: 23417515]

37. Mamo D, Graff A, Mizrahi R, Shammi C, Romeyer F, Kapur S. Differential effects of aripiprazole on D 2, 5-HT 2, and 5-HT 1A receptor occupancy in patients with schizophrenia: a triple tracer PET study. American Journal of Psychiatry. 2007; 164(9):1411-1417. [PubMed: 17728427]

38. Graff-Guerrero A, Mamo D, Shammi CM, et al. The effect of antipsychotics on the high-affinity state of D2 and D3 receptors: a positron emission tomography study With [11C]-(+)-PHNO. Arch Gen Psychiatry. 2009; 66(6):606-615. [PubMed: 19487625]

39. Mamo, David, MD, MSc, Graff, Ariel, MD, PhD, Mizrahi, Romina, MD, PhD, Shammi, CM., MD, Romeyer, Françoise, PD, Kapur, Shitij, MD, PhD. Differential Effects of Aripiprazole on D 2, 5-HT 2, and 5-HT 1A Receptor Occupancy in Patients With Schizophrenia: A Triple Tracer PET Study. American Journal of Psychiatry. 2007; 164(9):1411-1417. [PubMed: 17728427]

40. Chakravarty MM, Steadman P, van Eede MC, et al. Performing label-fusion-based segmentation using multiple automatically generated templates. Hum Brain Mapp. 2013; 34(10):2635-2654. [PubMed: 22611030]

41. Pipitone J, Park MT, Winterburn J, et al. Multi-atlas segmentation of the whole hippocampus and subfields using multiple automatically generated templates. Neuroimage. 2014; 101:494-512. [PubMed: 24784800]

42. Chakravarty MM, Bertrand G, Hodge CP, Sadikot AF, Collins DL. The creation of a brain atlas for image guided neurosurgery using serial histological data. Neuroimage. 2006; 30(2):359-376. [PubMed: 16406816]

43. Schuetze M, Park MTM, Cho IYK, MacMaster FP, Chakravarty MM, Bray SL. Morphological Alterations in the Thalamus, Striatum, and Pallidum in Autism Spectrum Disorder. Neuropsychopharmacology : official publication of the American College of Neuropsychopharmacology. 2016; 41(11):2627-2637. [PubMed: 27125303]

44. Plitman E, Patel R, Chung JK, et al. Glutamatergic Metabolites, Volume and Cortical Thickness in Antipsychotic-Naive Patients with First-Episode Psychosis: Implications for Excitotoxicity. 
Neuropsychopharmacology : official publication of the American College of Neuropsychopharmacology. 2016; 41(10):2606-2613. [PubMed: 27272768]

45. Eskildsen SF, Coupe P, Fonov V, et al. BEaST: brain extraction based on nonlocal segmentation technique. Neuroimage. 2012; 59(3):2362-2373. [PubMed: 21945694]

46. Kay SR, Fiszbein A, Opler LA. The positive and negative syndrome scale (PANSS) for schizophrenia. Schizophrenia Bulletin. 1987; 13(2):261-276. [PubMed: 3616518]

47. Wallwork RS, Fortgang R, Hashimoto R, Weinberger DR, Dickinson D. Searching for a consensus five-factor model of the Positive and Negative Syndrome Scale for schizophrenia. Schizophrenia research. 2012; 137(1-3):246-250. [PubMed: 22356801]

48. Messinger JW, Tremeau F, Antonius D, et al. Avolition and expressive deficits capture negative symptom phenomenology: implications for DSM-5 and schizophrenia research. Clin Psychol Rev. 2011; 31(1):161-168. [PubMed: 20889248]

49. Liemburg E, Castelein S, Stewart R, van der Gaag M, Aleman A, Knegtering H. Two subdomains of negative symptoms in psychotic disorders: Established and confirmed in two large cohorts. Journal of Psychiatric Research. 2013; 47(6):718-725. [PubMed: 23472837]

50. Fervaha G, Foussias G, Agid O, Remington G. Motivational and neurocognitive deficits are central to the prediction of longitudinal functional outcome in schizophrenia. Acta Psychiatr Scand. 2014; 130(4):290-299. [PubMed: 24850369]

51. Randolph C, Tierney MC, Mohr E, Chase TN. The Repeatable Battery for the Assessment of Neuropsychological Status (RBANS): preliminary clinical validity. Journal of clinical and experimental neuropsychology. 1998; 20(3):310-319. [PubMed: 9845158]

52. Ebdrup BH, Norbak H, Borgwardt S, Glenthoj B. Volumetric changes in the basal ganglia after antipsychotic monotherapy: a systematic review. Current medicinal chemistry. 2013; 20(3):438447. [PubMed: 23157636]

53. Jorgensen KN, Nesvag R, Gunleiksrud S, Raballo A, Jonsson EG, Agartz I. First- and secondgeneration antipsychotic drug treatment and subcortical brain morphology in schizophrenia. European archives of psychiatry and clinical neuroscience. 2016; 266(5):451-460. [PubMed: 26547434]

54. Kirschner M, Hager OM, Bischof M, et al. Ventral striatal hypoactivation is associated with apathy but not diminished expression in patients with schizophrenia. Journal of psychiatry \& neuroscience : JPN. 2016; 41(3):152-161. [PubMed: 26395814]

55. Wolf DH, Satterthwaite TD, Kantrowitz JJ, et al. Amotivation in schizophrenia: integrated assessment with behavioral, clinical, and imaging measures. Schizophr Bull. 2014; 40(6):13281337. [PubMed: 24657876]

56. Simon JJ, Biller A, Walther S, et al. Neural correlates of reward processing in schizophreniarelationship to apathy and depression. Schizophrenia research. 2010; 118(1-3):154-161. [PubMed: 20005675]

57. Mikell CB, McKhann GM, Segal S, McGovern RA, Wallenstein MB, Moore H. The Hippocampus and Nucleus Accumbens as Potential Therapeutic Targets for Neurosurgical Intervention in Schizophrenia. Stereotactic and Functional Neurosurgery. 2009; 87(4):256-265. [PubMed: 19556835]

58. Bikovsky L, Hadar R, Soto-Montenegro ML, et al. Deep brain stimulation improves behavior and modulates neural circuits in a rodent model of schizophrenia. Experimental neurology. 2016; 283(Pt A):142-150. [PubMed: 27302677]

59. Ma J, Leung LS. Deep brain stimulation of the medial septum or nucleus accumbens alleviates psychosis-relevant behavior in ketamine-treated rats. Behavioural brain research. 2014; 266:174182. [PubMed: 24632470]

60. Bewernick BH, Kayser S, Sturm V, Schlaepfer TE. Long-term effects of nucleus accumbens deep brain stimulation in treatment-resistant depression: evidence for sustained efficacy. Neuropsychopharmacology : official publication of the American College of Neuropsychopharmacology. 2012; 37(9):1975-1985. [PubMed: 22473055]

61. Hibar DP, Stein JL, Renteria ME, et al. Common genetic variants influence human subcortical brain structures. Nature. 2015; 520(7546):224-229. [PubMed: 25607358] 
62. Caprioli D, Sawiak SJ, Merlo E, et al. Gamma aminobutyric acidergic and neuronal structural markers in the nucleus accumbens core underlie trait-like impulsive behavior. Biological psychiatry. 2014; 75(2):115-123. [PubMed: 23973096]

63. Smiley JF, Saito M, Bleiwas C, et al. Selective reduction of cerebral cortex GABA neurons in a late gestation model of fetal alcohol spectrum disorder. Alcohol (Fayetteville, NY). 2015; 49(6):571580.

64. Hamilton GF, Hernandez IJ, Krebs CP, Bucko PJ, Rhodes JS. Neonatal alcohol exposure reduces number of parvalbumin-positive interneurons in the medial prefrontal cortex and impairs passive avoidance acquisition in mice deficits not rescued from exercise. Neuroscience. 2017; 352:52-63. [PubMed: 28391014]

65. Martin-Soelch C, Szczepanik J, Nugent A, et al. Lateralization and Gender Differences in the Dopaminergic Response to Unpredictable Reward in the Human Ventral Striatum. The European journal of neuroscience. 2011; 33(9):1706-1715. [PubMed: 21453423]

66. Zhang S, Hu S, Chao HH, Li CR. Hemispheric lateralization of resting-state functional connectivity of the ventral striatum: an exploratory study. Brain structure \& function. 2017; 222(6):2573-2583. [PubMed: 28110447]

67. Robert GH, Le Jeune F, Lozachmeur C, et al. Preoperative factors of apathy in subthalamic stimulated Parkinson disease: a PET study. Neurology. 2014; 83(18):1620-1626. [PubMed: 25253750] 
A. B.

Right Ventral Striatum

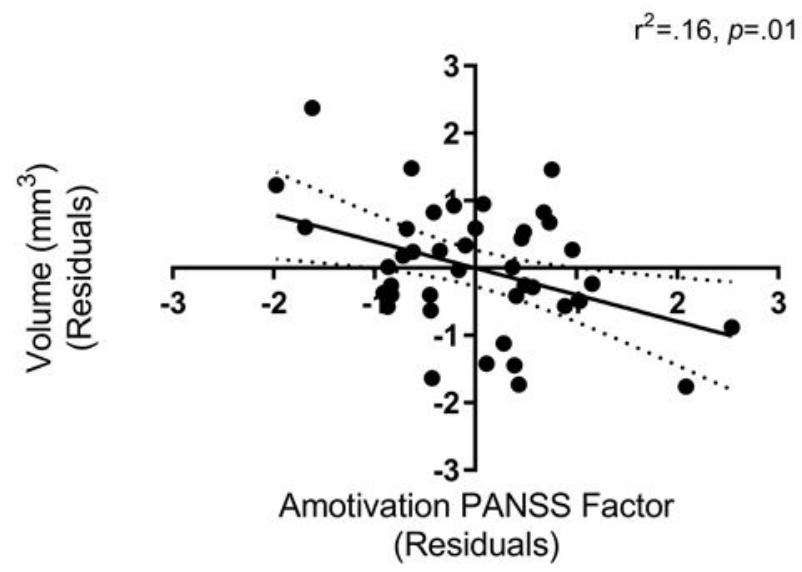

\section{Left Ventral Striatum}

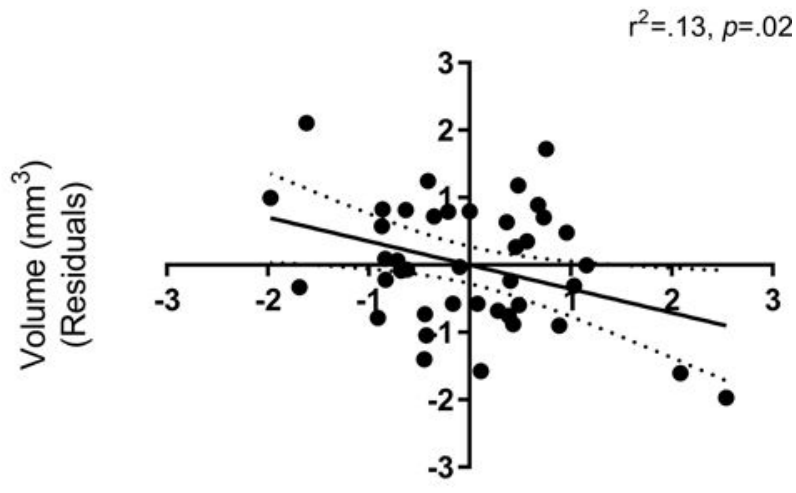

Amotivation PANSS Factor (Residuals)

Figure 1. 


\section{Table 1}

Subject characteristics.

\begin{tabular}{|c|c|}
\hline & $\begin{array}{c}\text { Total }(n=41) \\
\text { Mean } \pm \text { SD }(\text { range }) \text { or } n(\%)\end{array}$ \\
\hline Age (year) & $60.2 \pm 6.7(50-79)$ \\
\hline Female (n) & $11(26.8)$ \\
\hline African (n) & $4(9.8)$ \\
\hline Asian (n) & $2(4.9)$ \\
\hline Caucasian (n) & $35(85.4)$ \\
\hline Schizophrenia (n) & $33(80.5)$ \\
\hline Schizoaffective (n) & $8(19.5)$ \\
\hline Age of onset (year-old) & $25.1 \pm 9.7(7-48)$ \\
\hline Duration of illness (year) & $34.3 \pm 10.6(8-55)$ \\
\hline Number of episode (n) & $5.7 \pm 4.8(1-20)$ \\
\hline Number of hospitalization (n) & $5.9 \pm 5.4(0-20)$ \\
\hline Year of antipsychotic exposure (year) & $30.0 \pm 11.7(4-55)$ \\
\hline PANSS total score & $60.2 \pm 13.5(30-82)$ \\
\hline Positive subscale score & $12.8 \pm 3.9(7-20)$ \\
\hline Negative subscale score & $17.9 \pm 5(7-28)$ \\
\hline General psychopathology subscale score & $29.5 \pm 6.8(16-43)$ \\
\hline \multicolumn{2}{|l|}{ PANSS factor scores } \\
\hline Positive & $11.24 \pm 3.22(5-17)$ \\
\hline Negative & $22.83 \pm 6.70(10-36)$ \\
\hline Depression & $8.02 \pm 2.88(5-15)$ \\
\hline Disorganized & $7.24 \pm 2.44(3-13)$ \\
\hline Excited/Activation & $6.37 \pm 1.67(5-12)$ \\
\hline Amotivation Factor & $7.88 \pm 2.68(3-13)$ \\
\hline Diminished Expression Factor & $9.51 \pm 3.20(4-16)$ \\
\hline OLZ (n) & $24(58.5)$ \\
\hline Daily dose (mg) & $20.6 \pm 6.7(10-35)$ \\
\hline RIS (n) & $17(41.5)$ \\
\hline Daily dose (mg) & $4.3 \pm 2.5(2-12)$ \\
\hline CPZ equivalent dose (mg) & $419.5 \pm 186.4(200-1200)$ \\
\hline \multirow[t]{2}{*}{$\mathrm{D}_{2 / 3} \mathrm{R}$ occupancy $(\%)$} & $70.4 \pm 11.9(40.6-91.2)$ \\
\hline & $(\mathrm{n}=36)$ \\
\hline RBANS Total Scores & $76.53 \pm 11.64(52-99)$ \\
\hline
\end{tabular}

Abbreviations: PANSS, Positive and Negative Syndrome Scale; OLZ, Olanzapine; RIS, Risperidone; CPZ, Chlorpromazine; RBANS, Repeatable Battery for the Assessment of Neuropsychological Status. 


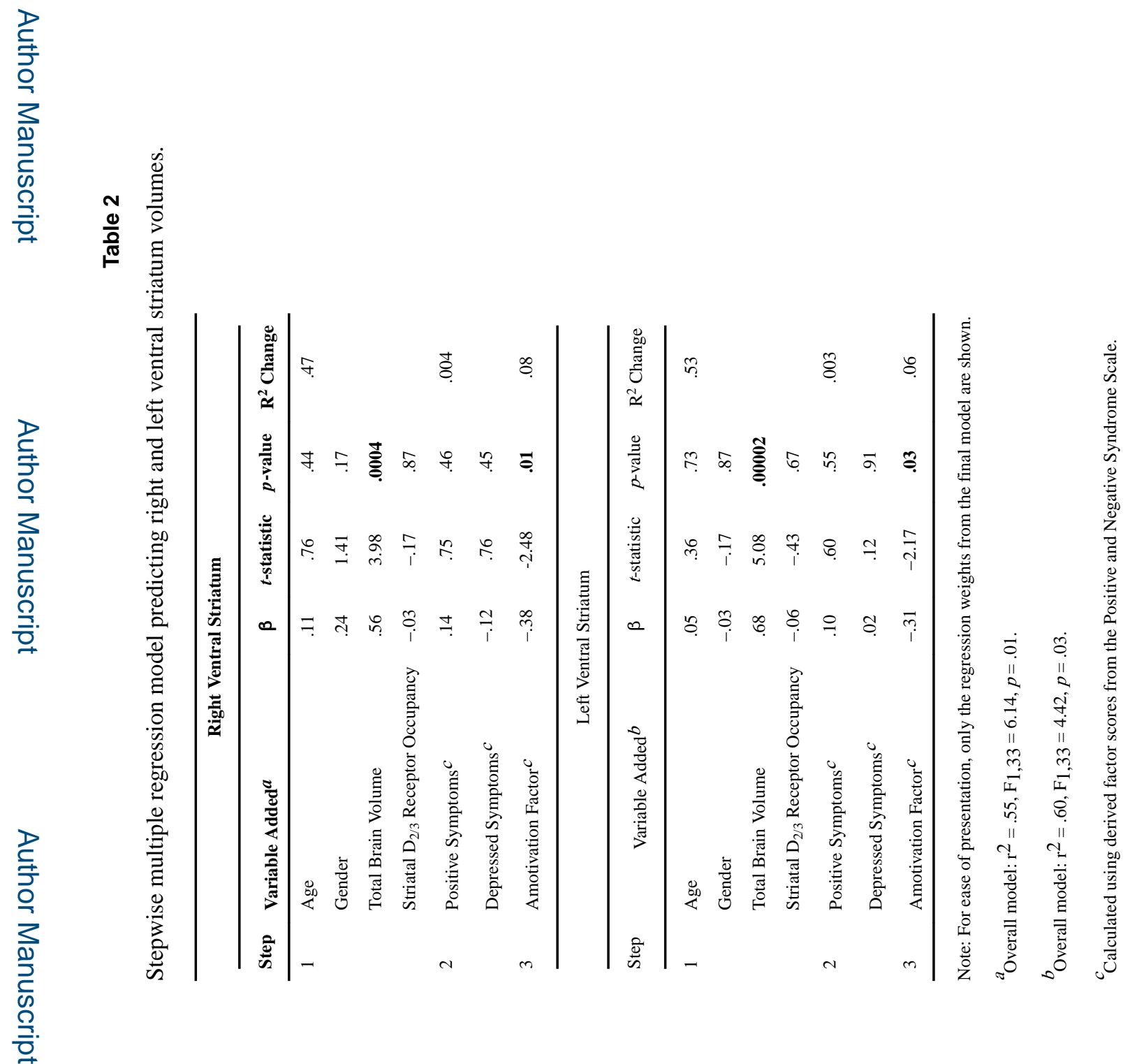



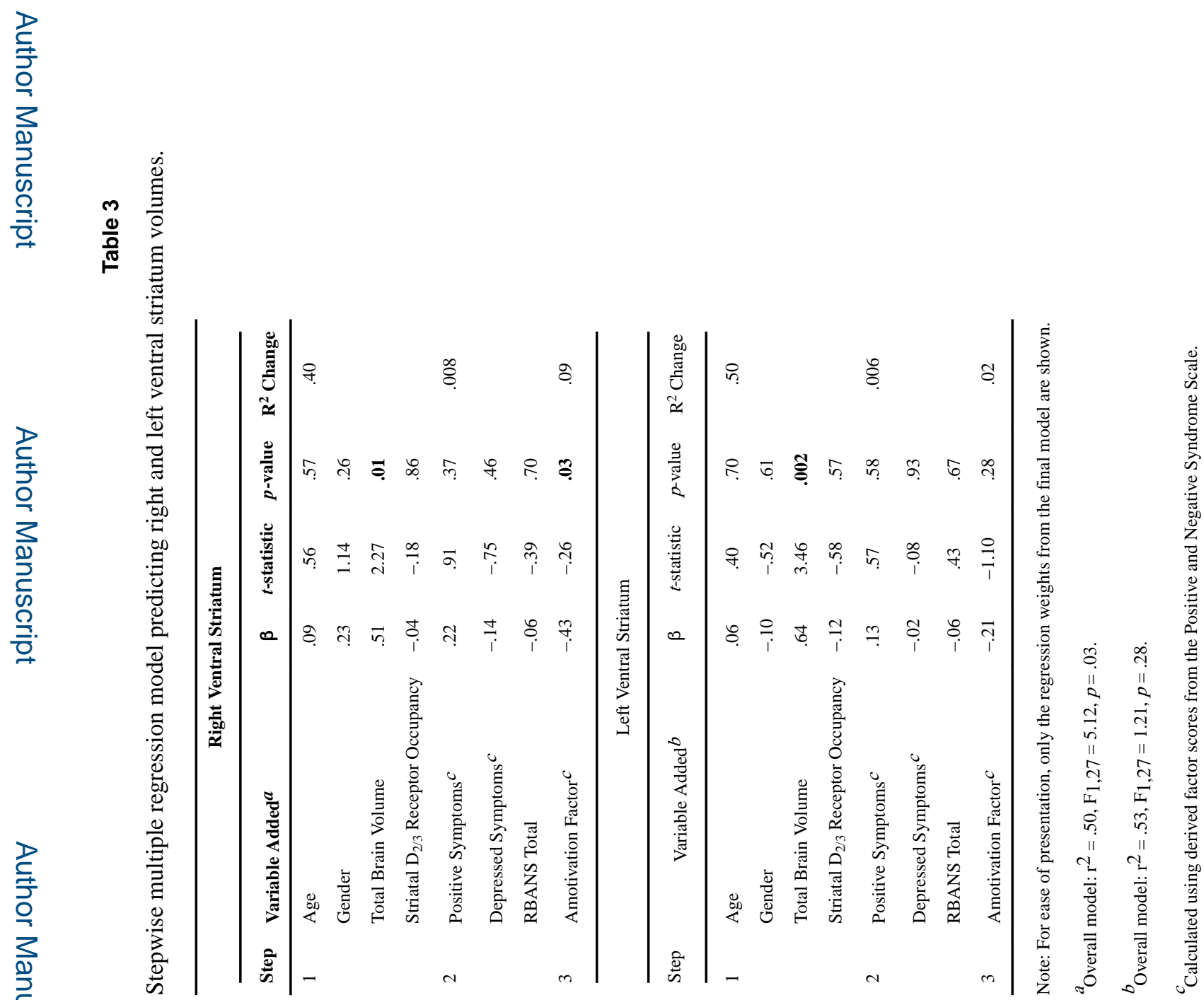


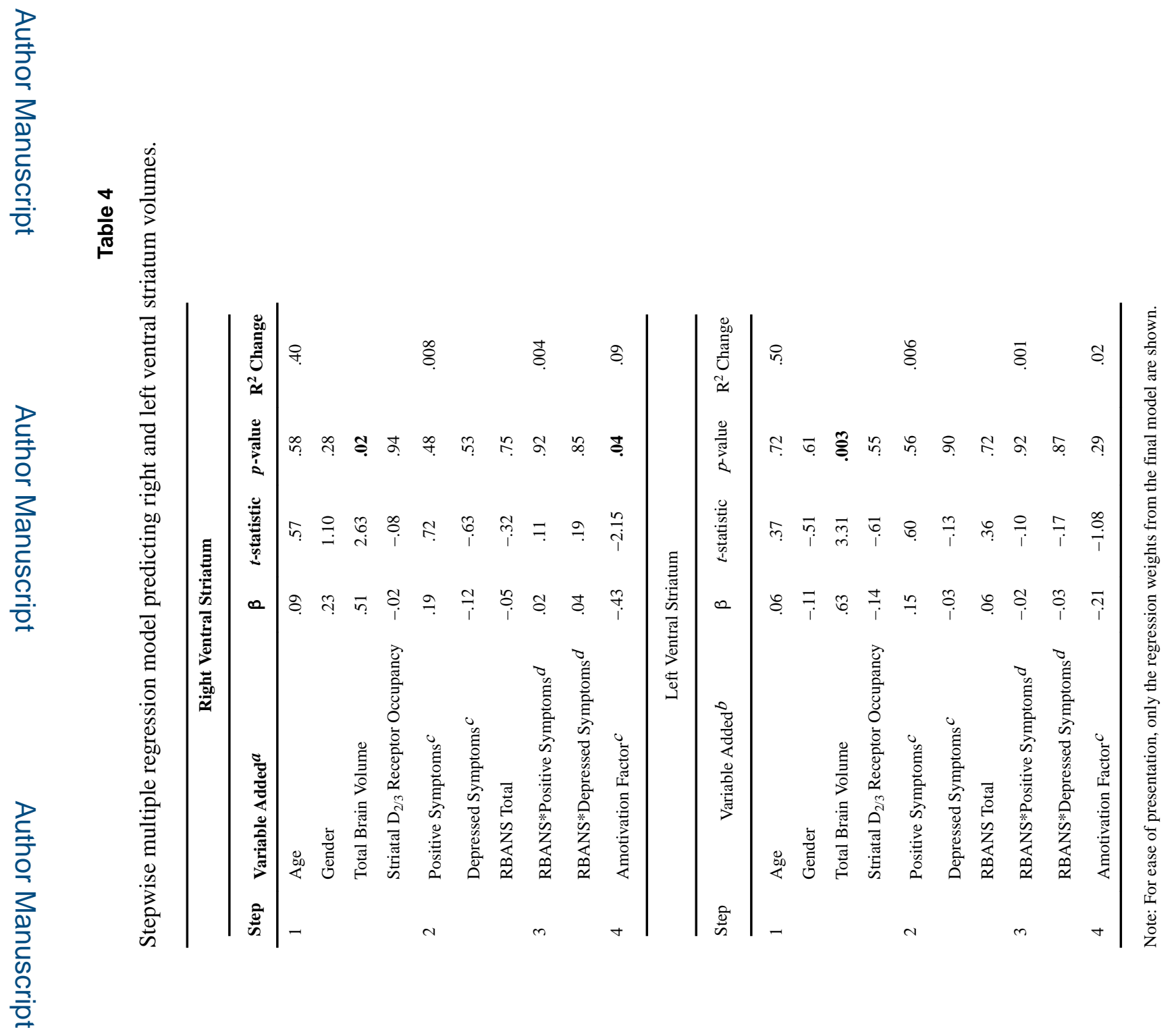





로을

Int J Geriatr Psychiatry. Author manuscript; available in PMC 2019 March 01. 